\title{
Abreaction for conversion disorder: systematic review with meta-analysis
}

Norman A. Poole, Axel Wuerz and Niruj Agrawal

\section{Background}

The value of drug interviews in the treatment of conversion disorder is at present unknown.

\section{Aims \\ To review all the available papers published in English that report on the use of drug interviews for treating conversion/ dissociative disorder.}

\section{Method}

Databases (including EMBASE, MEDLINE and PsycINFO) were searched from 1920 to 2009. Selected publications had to report on the use of drug interviews in people diagnosed with a conversion/dissociative disorder. Qualitative and quantitative data were extracted. Predictors of a positive response were ascertained using meta-analytic techniques.

\section{Results}

Fifty-five papers meeting inclusion criteria were identified. No studies compared the intervention with a suitable control group. However, two studies reported high response rates when drug interview was used in individuals with treatmentresistant conversion disorder. In the meta-analysis, the use of suggestion and occurrence of emotional catharsis during the interview were positively associated with recovery. combining two medications and comorbid psychiatric disorder were negatively associated with recovery.

\section{Conclusions}

The evidence for effectiveness of drug interviews is of poor quality but it may be of benefit in the treatment of acute and treatment-resistant conversion disorder. A proactive approach during the interview, making suggestions the individual will respond, could influence outcome. Comorbid psychiatric disorder should be treated conventionally. Experimental studies to determine efficacy are required.

\section{Declaration of interest}

None.
Conversion disorder, the development of neurological symptoms in the absence of demonstrable pathology, despite a recent revival in interest remains a relatively neglected field of medicine and psychiatry. ${ }^{1}$ This neglect may be partly explained by the skepticism towards the diagnosis that followed Slater's influential paper, ${ }^{2}$ which concluded that, given time, most hysterical states evolve into true neurological disease. This view has been successfully debunked $^{3}$ and conversion disorder is now seen to be a relatively stable psychiatric diagnosis ${ }^{4}$ with a frequently poor prognosis. ${ }^{5}$ Despite the renewed interest there remains a paucity of studies addressing therapy. Treatments including psychoeducation, cognitive-behavioural therapy, hypnosis and long-term analytical psychotherapy have been reported to be beneficial but lack a robust evidence base. ${ }^{6}$

Abreaction, which involves interviewing individuals under the influence of a drug, was once commonly used for conversion disorder. The name 'abreaction' is rather a misnomer as it more precisely describes just one of the techniques, 'emotional catharsis', that can be employed during the drug interview. The physician can also suggest that symptoms will resolve during the interview ('suggestion'); explore the psychological and social antecedents to symptom formation ('exploration'); gradually restore motor, sensory or other body functions ('rehabilitation'); and recordings of battle sounds have been employed for those with war-induced conversion states. Originally considered useful as both a treatment and diagnostic aid, on the one hand to discriminate between hysteria and malingering and on the other between hysteria and organic conditions, the high number of psychiatric casualties made it popular in the Second World War. ${ }^{7}$ Enthusiasm for its use became so widespread that Tilkin speculated, 'the future of [abreaction] is infinite and the possibilities endless. ${ }^{8}$ In fact, its use has gradually waned: a consequence, perhaps, of Slater's misgivings.

Given the severity of the condition and lack of evidence for any particular therapy, we consider a synthesis of the research timely. A great majority of existing evidence takes the form of case series and reports. Meta-analysis of case reports and series is an unusual but accepted methodology ${ }^{9}$ that has proven able to generate additional knowledge. ${ }^{10}$ Noting the wide variety of names for the procedure (see Method), we will keep to the more theory-neutral phrase 'drug interview' for the remainder of the paper.

\section{Method}

\section{Search and selection strategy for studies}

We searched MEDLINE (from 1950), PsycINFO (from 1920), EMBASE Classic (from 1947 to 1979), and EMBASE (from 1980 to September 2009). We used the key words ('conversion' OR 'dissoc *' OR 'hyster*' OR 'non-organic' OR 'psychogenic' OR 'psychosomatic' OR 'somatization' OR 'unexplained') AND ('abreaction' OR 'amobarbital' OR 'amytal' OR 'hypnoanalysis' OR 'narcoanalysis' OR 'narcocatharsis' OR 'narcosis' $O R$ 'narcosuggestion' OR 'narcosynthesis' OR 'nembutal' OR 'thiopentone'). Two of the authors (N.A.P. and N.A.) reviewed the titles and abstracts online and obtained copies of all publications that appeared relevant to the study question. The reference lists of all these publications were then hand searched for additional relevant studies.

Studies were included if the symptoms were described as medically unexplained, non-organic, psychogenic, hysterical, conversion or functional; the symptoms were described as motor (paresis, paralysis, movement disorder, gait disorder), sensory (numbness or paraesthesia), loss of vision, loss of hearing, muteness, stammer, sneezing, loss of personal identity, amnesia or episodes resembling epilepsy (non-epileptic attack disorder). Only papers in English were included. Papers were excluded if its authors concluded that the symptoms were attributable to 
deliberate feigning, or identified a comorbid psychotic disorder, as the symptoms could be psychotic or catatonic in nature.

\section{Data extraction and analysis}

Two authors (N.A.P. and N.A.) independently extracted all the relevant data from the papers and where they disagreed a third reviewer (A.W.) was consulted. We collected information about: the study design; year of publication; the gender and age of participants; type and duration of symptoms; whether symptoms arose in the context of battle or an identified stressor; the type of $\operatorname{drug}(\mathrm{s})$ used; the techniques described (classified as: emotional catharsis; suggestion; rehabilitation; exploration; and exposure to battle sounds); duration of follow-up; and outcome dichotomised into 'response' and 'non-response'. Where response to treatment was equivocal or not reported, this was considered 'non-response'. When information was incomplete, we attempted to contact the authors. Where a study was reported in more than one paper, we extracted data from the most relevant.

For the meta-analysis, continuous data such as age were first converted into categorical data. All the variables were then associated with clinical end-points by cross-tabulation (Pearson's chi-squared). Fisher's exact test was used when one or more cells in the $2 \times 2$ table contained five cases or fewer. Odds ratios (ORs) and $95 \%$ CIs were calculated on SPSS version 15.0.1 for Windows and a $P$ less than 0.05 was considered significant. Commonly, more than one therapeutic technique was used in the drug interview, therefore cases in which a particular technique was employed were compared with all the cases in which it was not used. Cases published before 1970 were compared with those published after this date to explore whether improvements in diagnostic accuracy ${ }^{4}$ influenced response.

\section{Results}

The search methodology identified 811 studies, 55 of which met the study inclusion criteria. Four studies were open-label trials, ${ }^{11-14}$ one a retrospective review of cases, ${ }^{15}$ but the majority $(n=51)$ took the form of case reports or series. ${ }^{12,16-65}$ One paper both reported individual cases and compared drug interviews for psychogenic versus organic deafness. ${ }^{12}$

The studies are presented in online Table DS1. A brief summary of the case reports and series can be seen in online Table DS2, which presents information on each participant, the drug and dosage used, number of drug interviews undertaken, techniques used during the interviews and a description of the outcome. The characteristics of the study population and results of statistical analyses are presented in Table 1 . The median age of participants was 29 years (range 10-74), and the mean duration of symptoms 49 days (range 3-3650). However, nearly a third of studies failed to report the duration of symptoms. The combination of two drugs for the interview involved administering midazolam $(n=1)$, ether $(n=4)$, methylphenidate $(n=7)$ or insulin $(n=1)$, along with the intravenous sedative.

\begin{tabular}{|c|c|c|c|c|c|}
\hline & Total, $n(\%)$ & Recovered, $n$ (\%) & Cross-tabulation & Odds ratio & $95 \% \mathrm{Cl}$ \\
\hline Total & 116 & $92(79)$ & & & \\
\hline \multicolumn{6}{|l|}{ Gender } \\
\hline Male & $79(70)$ & $62(78)$ & 0.70 & 0.63 & $0.21-1.87$ \\
\hline Female & $34(30)$ & $29(85)$ & 0.70 & 1.59 & $0.54-4.73$ \\
\hline \multicolumn{6}{|l|}{ Symptom type } \\
\hline Motor & $38(33)$ & $31(82)$ & 0.07 & 1.14 & $0.43-3.07$ \\
\hline Sensory & $15(13)$ & $13(87)$ & FET & 1.71 & $0.36-8.16$ \\
\hline Identity/amnesia & $24(21)$ & $21(88)$ & FET & 1.94 & $0.53-7.19$ \\
\hline Non-epileptic seizure & $7(6)$ & $6(86)$ & FET & 1.52 & $0.17-13.3$ \\
\hline Mutism & $16(14)$ & $11(69)$ & 1.52 & 0.48 & $0.15-1.56$ \\
\hline Mixed & $14(12)$ & $11(79)$ & FET & 0.89 & $0.23-3.51$ \\
\hline Atypical & $8(7)$ & $4(50)$ & $\mathrm{FET}^{*}$ & 0.21 & $0.05-0.93$ \\
\hline \multicolumn{6}{|l|}{ Age, years } \\
\hline$\leqslant 29$ & $52(45)$ & $41(79)$ & 0.07 & 1.14 & $0.44-2.94$ \\
\hline$\geqslant 30$ & $46(40)$ & $36(78)$ & 0.01 & 1.05 & $0.41-2.73$ \\
\hline \multicolumn{6}{|l|}{ Characteristics } \\
\hline Battle acquired & $32(28)$ & $25(78)$ & 0.12 & 0.84 & $0.31-2.28$ \\
\hline Stressor identified & $61(53)$ & $51(84)$ & 0.95 & 1.58 & $0.63-3.96$ \\
\hline Acute (<6 months) & $49(42)$ & $40(82)$ & 0.37 & 1.41 & $0.46-4.32$ \\
\hline Chronic ( $\geqslant 6$ months) & $29(19)$ & $22(76)$ & 0.37 & 0.70 & $0.23-2.16$ \\
\hline Psychiatric comorbidity & $31(27)$ & $21(68)$ & $4.11 *$ & 0.38 & $0.15-0.99$ \\
\hline \multicolumn{6}{|l|}{ Drug } \\
\hline Barbiturate & $104(90)$ & $84(81)$ & 0.22 & 1.40 & $0.35-5.65$ \\
\hline Benzodiazepine & $5(5)$ & $4(80)$ & FET & 0.99 & $0.10-9.29$ \\
\hline Additional medication & $15(13)$ & $9(60)$ & $4.41^{*}$ & 0.30 & $0.10-0.97$ \\
\hline \multicolumn{6}{|l|}{ Study conditions } \\
\hline Follow-up provided & $40(34)$ & $30(75)$ & 1.03 & 0.62 & $0.24-1.57$ \\
\hline Published pre-1970 & $69(59)$ & $56(80)$ & 0.10 & 1.16 & $0.46-2.93$ \\
\hline \multicolumn{6}{|l|}{ Technique used } \\
\hline Exploration & $83(72)$ & $67(81)$ & 0.06 & 1.04 & $0.77-1.40$ \\
\hline Suggestion & $48(41)$ & $44(92)$ & $6.80 * *$ & 4.27 & $1.35-13.5$ \\
\hline Emotional catharsis & $31(27)$ & $29(94)$ & $4.76^{*}$ & 4.76 & $1.04-21.7$ \\
\hline Rehabilitation & $15(13)$ & $10(67)$ & 1.98 & 0.43 & $0.13-1.42$ \\
\hline Battle sounds & $14(12)$ & $10(71)$ & 0.77 & 0.57 & $0.16-2.02$ \\
\hline $\begin{array}{l}\text { FET, Fisher's exact test. } \\
{ }^{*} P<0.05,{ }^{*} P<0.01\end{array}$ & & & & & \\
\hline
\end{tabular}


Follow-up was specified for 32 participants and ranged from 1 to 60 months $($ mean $=2.17)$.

\section{Discussion}

This study is the first to synthesise all evidence published in English on drug interviews in conversion disorder. By performing a metaanalysis of case reports it has also been possible to identify predictors of a dichotomised outcome. As papers reporting unsuccessful cases are less likely either to be written or published, no conclusions regarding effectiveness can be drawn. However, two of the largescale studies ${ }^{7,8}$ utilised drug interviews only in those unresponsive to standard therapy and both report very high response rates.

The most striking feature of the evidence is the apparent beneficence of suggestion. Suggestions are verbal communications that a specific non-volitional response will be experienced by the recipient. ${ }^{66}$ These communications are statistically associated with a good outcome in the meta-analysis; employed in all of the large studies; and were a constant in Hafeiz's trial. ${ }^{14}$ This study randomly assigned participants to one of four experimental treatments (faradic stimulation; Somlec, a machine that induces sleep; intravenous (IV) methylphenidate; or IV amytal), but sadly omitted a control group. Over $80 \%$ of participants receiving one of the first three procedures, allied with suggestion, recovered. A much lower response rate (20\%) was seen in the amytal group, although this treatment was discontinued after only five participants somewhat undermining the original study design. Given the experimental and frankly dubious treatments employed some will not resist the conclusion that this study merely reveals those liable to conversion disorder are biddable by nature. However, if conversion disorder is amenable to suggestion then it is worth considering why this should be so.

Susceptibility to suggestion has long been identified with conversion disorder. Babinski, a pupil of Charcot's, went so far as to call the condition pithiatisme, that is, suggestibility. ${ }^{67}$ Pierre Janet, who believed suggestibility occurs only in hysterics and disappears on recovery, regarded it as the tendency for a simple idea, internally or externally generated, to develop into automatous complex chains of association that exert an effect over the body outwith conscious control. ${ }^{68}$ In this model, restored neurological function could be suggested and the idea of this would quickly gain purchase in the individual. However, for Janet this would not constitute a cure as the tendency to suggestibility persists.

Suggestions may influence the placebo response. Elaborate medical procedures involving injection are thought to enhance the placebo element of a treatment, ${ }^{69}$ which in any case is known to be high in subjectively distressing conditions, such as pain and depression. ${ }^{70}$ A major explanatory model for the placebo response is expectancy theory: a placebo treatment produces an expectation of a certain effect, which the expectation itself produces. ${ }^{70}$ It may produce this by ameliorating anxiety; reducing negative cognitions while strengthening coping cognitions that cause salutary modifications in behaviour and arousal; or by directly affecting physiological pathways specific to the particular expectation. Expectancies are influenced by the information given about the placebo. So a placebo can cause sedation or stimulation depending on the alleged effect. In drug interviews the use of suggestions augmented by the drama of the procedure is likely to raise the expectancy of recovery and challenge dysfunctional health beliefs that cause and maintain the condition. The active drug may supplement the placebo response without directly influencing the conversion symptoms. The altered psychic state may confirm that 'something is happening', which lends further credence to the expectancies.

Interviews under the influence of drugs were developed as a simpler alternative to hypnosis, ${ }^{7}$ hence its original title "narcosis: a narcotic-induced hypnosis'. This state was thought to render individuals hyper-suggestible and hysterics were thought to be uniquely or particularly hypnotisable. ${ }^{7}$ A special hypnoid state is no longer thought to exist, rather the experience of hypnosis is also based upon expectancies. ${ }^{66}$ For example, the majority of those who anticipate amnesia for the hypnotic 'trance' will experience this while none of those who do not expect such an eventuality do so. However, perhaps the potentiation of gamma-aminobutyric acid function in limbic and cortical regions caused by benzodiazepines and barbiturates renders the person more suggestible. This has been shown to occur with sodium amytal injections, ${ }^{71}$ although the precise mechanism remains unclear. To summarise, suggestibility may be a feature of conversion disorder, a drug effect or mechanism behind the placebo response.

The participant achieving an 'emotional catharsis' during the interview is also positively associated in the meta-analysis with amelioration of conversion symptoms and reported by Semenov to occur during most successful treatments. ${ }^{12}$ The curative power of catharsis in conversion disorder was first noted by Bertha Pappenheim, ${ }^{72}$ better known as Anna O. Breuer's case in Studies in Hysteria. ${ }^{73}$ She found that by recalling the circumstance of a symptom's onset, a reliving of the emotional experience was followed by resolution of the symptom. Breuer and Freud believed the symptoms were caused by increased energy in the neurological system associated with repressed traumatic memories and that catharsis was a means to purge this excess. Freud found he could not reliably induce hypnosis, ${ }^{74}$ which Breuer held to be necessary for the process, and so moved on to examine transference and the symbolic value of symptoms. This hydraulic conception of the mind/brain has long been discredited, ${ }^{75}$ but the observation may still have some validity.

If repressed traumatic memories are genuinely retrieved during the interview then it is likely the participant will be affected by their recollection. It is not a matter of expunging some packet of energy but reintegrating an upsetting experience, which is closer to Janet's conception of hysteria as dissociation. ${ }^{76}$ Alternatively, in a model similar to one proposed for posttraumatic stress disorder, the eliciting of avoided traumatic memories will induce anxiety, which reduces through habituation to the traumatic memory. However, many of the life events linked with conversion disorder are stressful rather than traumatic in nature. ${ }^{77}$ The finding may of course be an artifact. Many of the clinicians who reported catharsis will have been at least implicitly influenced by Freud and Breuer's model. All emotional displays may have been perceived in this light and the clinicians' expectations will subtly influence their patient's behaviour.

It has traditionally been thought that chronic conversion symptoms are less amenable to drug interview, ${ }^{78}$ and Lal \& Sharma ${ }^{13}$ report much lower response rates in those with symptoms lasting 6 weeks or longer. The natural history of the disorder may explain this observation as the majority of people with acute conversion symptoms leave hospital recovered or greatly improved ${ }^{79}$ without recourse to drug interviews. Also, chronicity of symptoms is known to carry a poorer prognosis. ${ }^{80}$ As symptom duration of 6 months or greater is not associated with non-response in the meta-analysis and some participants responded despite having symptoms lasting many years, ${ }^{19,28,43}$ drug interviews may have a role in people with chronic, treatment-resistant conversion disorder .

Likewise, it has been claimed that drug interviews are of most value in individuals with dissociative identity disorder. ${ }^{81}$ However, 
in the meta-analysis only atypical symptoms, such as sneezing and stammering, are associated with poor response.

Comorbid mental illness is found in more than $50 \%$ of those with conversion disorder ${ }^{3}$ but in only $27 \%$ of our sample. The most common psychiatric diagnosis found is personality disorder, although this was not recorded in any of the cases (Table DS2), which probably reflects underreporting in the reports. Personality disorder indicates a poor prognosis, ${ }^{82}$ whereas the opposite is true for affective disorder. ${ }^{3}$ However, the presence of a comorbid psychiatric disorder was associated with a lower chance of responding to the drug interview. It is likely this is because drug interviews are ineffective in the treatment of affective disorders. ${ }^{49}$

Also negatively associated with response is the use of two medications during the procedure, although a number of different pharmacological agents were used so this result must be interpreted with caution. The rationale for adding a stimulant, usually methylphenidate or ether, is to induce emotional catharsis through hyperexcitability. ${ }^{83}$ Therefore, it is interesting that the occurrence of emotional catharsis is associated with recovery, whereas the use of additional medication is not.

\section{Limitations}

The study is limited by publication bias, quality of information in the case reports, small study population, and generalisability of the findings. Publication bias is of greatest concern when assessing the efficacy of a treatment, which this study did not seek to do. That males are so prevalent indicates bias may have occurred, perhaps limiting how far these results can be generalised to females with conversion disorder. It has been argued that the incidence in men and women is equal but doctors operate a bias against making the diagnosis in men. ${ }^{84}$ However, that clearly cannot account for this discrepancy. Few of the case reports used operationalised criteria to establish the diagnosis of hysteria, and even if they had the intension and extension of the definition has shifted since the first report in 1936 to the most recent.

The techniques employed during a drug interview are also not yet formalised and may differ significantly between practitioners, hindering interpretation of the positive results. Ideally, the combination of techniques used should be compared with all those in which that combination was not used. However, there are 25 possible combinations, which would preclude statistical analysis.

The duration of follow-up was frequently short or unspecified, although curiously outcome was not influenced by whether follow-up took place or not. Adverse events were not recorded in any of the case reports other than one serious suicide attempt in a participant with comorbid depressive disorder. ${ }^{48}$ Extracting data from case reports is another source for potential bias as a degree of interpretation is required. The authors minimised this by ensuring more than one author extracted the data. Although the total sample size is relatively small, it is the most complete data-set of papers in English. The small size is more likely to have resulted in missing potentially relevant associations.

\section{Implications}

The evidence suggests that drug interviews can be a useful treatment for individuals with both acute and treatment-resistant conversion disorder, although it is as yet unclear if the response is maintained in the long term. It is salutary to recall that the drug interview was originally developed as the first step in a treatment regimen rather than an entire therapy of itself. ${ }^{7}$ Perhaps a temporary resolution of symptoms is sufficient to initiate treatment aimed at the maintaining factors. An active approach to the interview, making use of suggestions before, during and after, is to be recommended. There is as yet insufficient evidence to recommend a particular drug, although most psychiatrists will feel more comfortable using the relatively safe and reversible benzodiazepines. If psychiatric comorbidity is present it should be treated independently.

The absence of rigorous randomised controlled trials indicates that the declining use of abreaction as a treatment for conversion disorder has not been an evidence-based decision. The procedure along with its various components is amenable to double-blind randomised control trial. This will clarify whether the administration of a drug is epiphenomenal to the drama and spectacle of the procedure. Given the burden of chronic conversion disorder and the relative safety of drug interviews (with appropriate precautions), such studies are required with some urgency.

Norman A. Poole, MBChB, MRCPsych, MSC, St Bartholomew's Hospital, East London Foundation Trust, London, UK; Axel Wuerz, MRCPsych, Department of Psychiatry, Marmara University, Istanbul, Turkey; Niruj Agrawal, MBBS, MD, MSC, MRCPsych, Dip CBT, Department of Neuropsychiatry, St George's Hospital, London, UK

Correspondence: Norman A. Poole, MBChB, MRCPsych, MSC, Locum Consultant Liaison Psychiatrist, St Bartholomew's Hospital, East London Foundation Trust, West Smithfield, London EC1A 7BE, UK. Email: Foundation Trust, West Smithfie
norman.poole@googlemail.com

First received 3 Apr 2009, final revision 8 Dec 2009, accepted 20 Apr 2010

\section{Acknowledgements}

The authors thank Dr Jonathan Bird for his helpful comments on an earlier draft of this paper.

\section{References}

1 Bass C, Peveler R, House A. Somatoform disorders: severe psychiatric illnesses neglected by psychiatrists. Br J Psychiatry 2001; 179: 11-14.

2 Slater ET, Glithero E. A follow-up of patients diagnosed as suffering from 'hysteria'. J Psychosom Res 1965; 9: 9-13.

3 Crimlisk HL, Bhatia K, Cope H, David A, Marsden CD, Ron MA. Slater revisited: 6 year follow up study of patients with medically unexplained motor symptoms. BMJ 1998; 316: 582-6.

4 Stone J, Smyth R, Carson A, Lewis S, Prescott R, Warlow C, et al. Systematic review of misdiagnosis of conversion symptoms and 'hysteria'. BMJ 2005; 331: 989.

5 Carson AJ, Best S, Postma K, Stone J, Warlow C, Sharpe M. The outcome of neurology outpatients with medically unexplained symptoms: a prospective cohort study. J Neurol Neurosurg Psychiatry 2003; 74: 897-900.

6 Ruddy R, House A. Psychosocial interventions for conversion disorder. Cochrane Database Syst Rev 2005; 4: CD005331.

7 Horsley JS. Narco-analysis. A New Technique in Short-cut Psychotherapy: A Comparison with other Methods and Notes on the Barbiturates. Oxford University Press, 1943.

8 Tilkin L. The present status of narcosynthesis using sodium pentothal and sodium amytal. Dis Nerv Syst 1949; 10: 215.

9 Vandenbroucke JP. In defense of case reports and case series. Ann Intern Med 2001; 134: 330-4.

10 Trabert W. 100 years of delusional parasitosis. Meta-analysis of 1,223 case reports. Psychopathology 1995; 28: 238-46.

11 Lambert C, Rees WL. Intravenous barbiturates in the treatment of hysteria. BMJ 1940; 2: 70-3.

12 Semenov $\mathrm{H}$. Deafness of psychic origin and its response, to narcosynthesis. Trans Am Ophthalmol Otolaryngol 1947; 2: 326-48.

13 Lal N, Sharma M. Role of narcosuggestions in hysteria. Indian J Psychiatry 1978; 20: 71-5.

14 Hafeiz HB. Hysterical conversion: a prognostic study. Br J Psychiatry 1980; 136: $548-51$.

15 Carter $\mathrm{AB}$. The prognosis of certain hysterical symptoms. BMJ 1949; 1 : 1076-9.

16 Horsley JS. Narco-analysis. J Ment Sci 1936; 82: 416-22. 
17 Herman M. The use of intravenous sodium amytal in psychogenic amnestic states. Psychiatr Q 1938; 12: 738-42.

18 Wilde JF. Narco-analysis in the treatment of war neuroses. BMJ 1942; 2: 4-7.

19 Sullivan DJ. Psychiatric uses of intravenous sodium amytal. Am J Psychiatry 1942; 99: 411-8.

20 Morris DP. Intravenous barbiturates: an aid in the diagnosis and treatment of conversion disorder and malingering. Mil Surg 1945; 96: 509-18.

21 Greiber MF. Narcosynthesis in the treatment of the noncombatant psychiatric casualty overseas. War Med 1945; 8: 85-90.

22 Bender MB, O'Brien FH. The influence of barbiturate on various forms of nystagmus. Am J Ophthalmol 1946; 29: 1541-52.

23 Rosen $\mathrm{H}$, Myers H. Abreaction in the military setting. Arch Neurol Psychiatry 1947; 57: 161-72.

24 Hannah HB. The treatment of hysteria by narco-hypnosis. Minn Med 1947; 30: $305-9$.

25 Myerson A. The treatment of hysteric amnesia by purely pharmacologic means. N Engl J Med 1947; 236: 821-3.

26 Ripley HS, Wolf S. The intravenous use of sodium amytal in psychosomatic disorders. Psychosom Med 1947; 9: 260-8.

27 Kupper WH. Observations on the use of a phonograph record of battle sounds employed in conjunction with pentothal in the treatment of 14 cases of severe conversion hysteria caused by combat. J Nerv Ment Dis 1947; 105 56-60.

28 Shorvon HJ, Sargant W. Excitatory abreaction: with special reference to its mechanism and the use of ether. J Ment Sci 1947; 393: 709-32.

29 Mueller EE, Kaney EM. Demonstrative clinical teamwork in the treatment of conversion hysteria. Psychiatr Q 1947; 21: 431-46.

30 Fisher C, Joseph ED. Fugue with awareness of loss of personal identity. Psychoanal Q 1949; 18: 480-93.

31 Arentsen K. Psychogenic deafness: a survey and a psychiatric study. Acta Psychiatr Neurol Scand 1954; 29: 391-410.

32 King PF. Psychogenic deafness. J Laryngol Otol 1954; 68: 623-35.

33 Mann J. The use of sodium amobarbital in psychiatry. Ohio Med J 1969; 65 700-2.

34 Hoffman PB, Faris AM. Psychiatric interventions with amnestic aircraft accident survivors. Aerospace Med 1974; 45: 1286-90.

35 Wettstein RM, Fauman BJ. The amobarbital interview. Ann Emerg Med 1979; 8: $272-4$.

36 Iserson KV. The emergency amobarbital interview. Ann Emerg Med 1980; 9 ; 27-31.

37 Shale JH, Gelenberg AJ. The amobarbital interview. Mil Med 1980; 145 825-8.

38 Perry JC, Jacobs D. Overview: clinical applications of the amytal interview in psychiatric emergency settings. Am J Psychiatry 1982; 139: 552-9.

39 Chancellor AM, Fraser AR. Dissociative disorder, conversion disorder and the use of abreaction in a 22 year old male. N Z Med J 1982; 95: 418-9.

40 Schwartze GM, Mchenry LC, Proctor RC. Convergence spasm - treatment by amytal interview. J Clin Neuroophthalmol 1983; 3: 123-5.

41 Weller EB, Weller RA. Case report of conversion symptom associated with major depressive disorder in a child. Am J Psychiatry 1983; 140: 1079-80.

42 Markowitz J, Viederman M. A case of dissociative pseudodementia. Gen Hosp Psychiatry 1986; 8: 87-90.

43 Stevens $\mathrm{H}$. Is it organic or is it functional? Is it hysteria or is it malingering? Psychiatr Clin North Am 1986; 9: 241-54.

44 Marcum JM, Wright K, Bissell WG. Chance discovery of multiple personality disorder in a depressed patient by amobarbital interview. J Nerv Ment Dis 1986; 174: 489-92.

45 Hendler N, Filtzer D, Talo S, Panzetta M, Lond D. Hysterical scoliosis treated with amobarbital narcosynthesis. Clin J Pain 1987; 2: 179-82.

46 White A, Corbin DOC, Coope B. The use of thiopentone in the treatment of non-organic locomotor disorder. J Psychosom Res 1988; 32: 249-53.

47 Hurwitz TA. Narcosuggestion in chronic conversion symptoms using combined intravenous amobarbital and methylphenidate. Can J Psychiatry 1988; 33: 147-52.

48 Menza MA. A suicide attempt following removal of conversion paralysis with amobarbital. Gen Hosp Psychiatry 1989; 11: 137-9.

49 Freimer N, Lu F, Chen J. Posttraumatic stress and conversion disorders in a maotian refugee veteran: use of amobarbital interviews. J Nerv Ment Dis 1989; 177: 432-3.

50 Hurwitz TA. Ideogenic neurological deficits: conscious mechanisms in conversion symptoms. Neuropsychiatry Neuropsychol Behav Neurol 1989; 1 301-8.
51 Stevens CB. Lorazepam in the treatment of acute conversion disorder. Hosp Community Psychiatry 1990; 41: 1255-7.

52 Ellis SJ. Diazepam as a truth drug. Lancet 1990; 336: 752-3.

53 Matas M. Psychogenic voice disorders: literature review and case report. Can J Psychiatry 1991; 36: 363-5.

54 Sengupta SN, Jena S, Saxena S. Generalised dissociative amnesia. Aust NZ J Psychiatry 1993; 27: 699-700.

55 Stiebel VG. The amytal interview in the treatment of conversion disorder: three case reports. Mil Med 1994; 159: 350-53.

56 Kopelman MD, Christensen H, Puffett A, Stanhope N. The great escape: neuropsychological study of psychogenic amnesia. Neuropsychologia 1994; 32: 675-91.

57 Nicolson R, Feinstein A. Conversion, dissociation, and multiple sclerosis. J Nerv Ment Dis 1994; 182: 668-9.

58 Fochtmann $\sqcup$. Intractable sneezing as a conversion symptom. Psychosomatics 1995; 36: 103-12.

59 Graham C, Thavasotby R. Dissociative psychosis: an atypical presentation and response to cognitive-analytic therapy. Ir J Psychol Med 1995; 12: 109-11.

60 Bradley RH, Zonia CL, Caputo SJ. The amobarbital sodium interview in conversion disorders: use of video feedback in therapy. J Am Osteopath Assoc 1995; 95: 122-5.

61 Fackler SM, Anfinson TJ, Rand JA. Serial sodium amytal interviews in the clinical setting. Psychosomatics 1997; 38: 558-64.

62 Al-Samarrai SH, Kramer E, Newmark T. Palilalia as a conversion disorder Psychosomatics 2001; 42: 277-8.

63 Ballew L, Morgan Y, Lippmann S. Intravenous diazepam for dissociative disorder: memory lost and found. Psychosomatics 2003; 44: 346-7.

64 Ilechukwu STC, Henry T. Amytal interview using intravenous lorazepam in a patient with dissociative fugue. Gen Hosp Psychiatry 2006; 28: 544-5.

65 Vattakatuchery JJ, Cesterman P. The use of abreaction to recover memories in psychogenic amnesia: a case report. J Forensic Psychiatry Psychol 2006; 17: 647-53.

66 Kirsch I. Hypnosis and placebos: response expectancy as a mediator of suggestion effects. Anales de Psicologia 1999; 15: 99-110.

67 Merskey $\mathrm{H}$. The Analysis of Hysteria: Understanding Conversion and Dissociation. Gaskell, 1995.

68 Janet P. The Major Symptoms of Hysteria: Fifteen Lectures Given in The Medical School of Harvard University. Macmillan \& Co, 1907.

69 Kaptchuk TJ, Goldman P, Stone DA, Stason WB. Do medical devices have enhanced placebo effects? J Clin Epidemiology 2000; 53: 786-92.

70 Stewart-Williams S, Podd J. The placebo effect: dissolving the expectancy versus conditioning debate. Psychol Bull 2004; 130: 324-40.

71 Eysenck HJ, Rees WL. States of heightened suggestibility: narcosis. J Ment Sci 1945; 91: 301-10.

72 Jones E. Sigmund Freud: Life and Work, Vol. 1. Hogarth Press, 1953.

73 Freud S, Breuer J. Studies in Hysteria. Penguin Books, 2004

74 Freud S. The Origins of Psycho-Analysis. Letters to Wilhelm Fliess, Drafts and Notes: 1887-1902. Basic Books, 1954

$75 \mathrm{McDougall} W$. The revival of emotional memories and its therapeutic value (III). Br J Med Psychol 1920; 1: 23-9.

76 van der Hart O, Brown P. Abreaction re-evaluated. Dissociation 1992; 5 $127-40$

77 Craig TKJ. Life events: meanings and precursors. In Contemporary Approaches to the Study of Hysteria: Clinical and Theoretical Perspectives (eds P Halligan, C Bass, JC Marshall): 88-101. Oxford University Press, 2001

78 Naples M, Hackett TP. The amytal interview: history and current uses. Psychosomatics 1978; 19: 98-105.

79 Binzer M, Kullgren G. Motor conversion disorder - a prospective 2-5 year follow-up study. Psychosomatics 1998; 39: 519-27.

80 Ron MA. The prognosis of hystera/somatization disorder. In Contemporary Approaches to the Study of Hysteria: Clinical and Theoretical Perspectives (eds P Halligan, C Bass, JC Marshall): 271-82. Oxford University Press, 2001.

81 Kavirajan $\mathrm{H}$. The amobarbital interview revisited: a review of the literature since 1966. Harv Rev Psychiatry 1999; 7: 153-65.

82 Mace CJ, Trimble MR. Ten-year prognosis of conversion disorder. $\mathrm{Br} \mathrm{J}$ Psychiatry 1996; 169: 282-8.

83 Sargant W, Slater E. An Introduction to Physical Methods of Treatment in Psychiatry. Churchill Livingstone, 1944.

84 Chodoff P. The diagnosis of hysteria: an overview. Am J Psychiatry 1974; 131: 1073-8. 